\title{
Groundwater Quality in the Colorado River Basins, California
}

Groundwater provides more than $\mathbf{4 0}$ percent of California's drinking water. To protect this vital resource, the State of California created the Groundwater Ambient Monitoring and Assessment (GAMA) Program. The Priority Basin Project of the GAMA Program provides a comprehensive assessment of the State's groundwater quality and increases public access to groundwater-quality information. Four groundwater basins along the Colorado River make up one of the study areas being evaluated.

\section{The Colorado River Study Area}

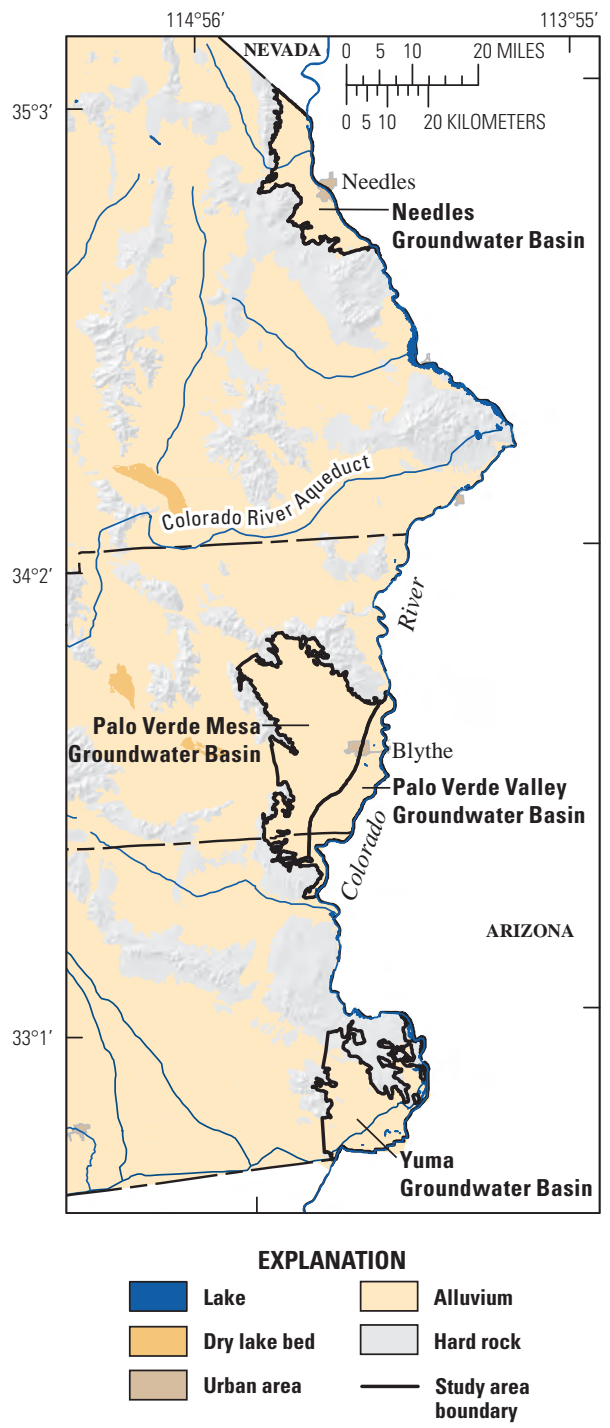

The Colorado River study area is approximately 884 square miles (2,290 square kilometers) and includes the Needles, Palo Verde Mesa, Palo Verde Valley, and Yuma groundwater basins (California Department of Water Resources, 2003). The Colorado River study area has an arid climate and is part of the Sonoran Desert. Average annual rainfall is about 3 inches (8 centimeters). Land use in the study area is approximately 47 percent (\%) natural (mostly shrubland), 47\% agricultural, and $6 \%$ urban. The primary crops are pasture and hay. The largest urban area is the city of Blythe (2010 population of 21,000).

Groundwater in these basins is used for public and domestic water supply and for irrigation. The main waterbearing units are gravel, sand, silt, and clay deposited by the Colorado River or derived from surrounding mountains. The primary aquifers in the Colorado River study area are defined as those parts of the aquifers corresponding to the perforated intervals of wells listed in the California Department of Public Health database. Public-supply wells in the Colorado River basins are completed to depths between 230 and 460 feet (70 to 140 meters), consist of solid casing from the land surface to a depth of 130 of 390 feet (39 to 119 meters), and are screened or perforated below the solid casing. The main source of recharge to the groundwater systems in the Needles, Palo Verde Mesa, and Palo Verde Valley basins is the Colorado River; in the Yuma basin, the main source of recharge is from subsurface flow from the groundwater basins to the west. Groundwater discharge is primarily to pumping wells, evapotranspiration, and, locally, to the Colorado River.

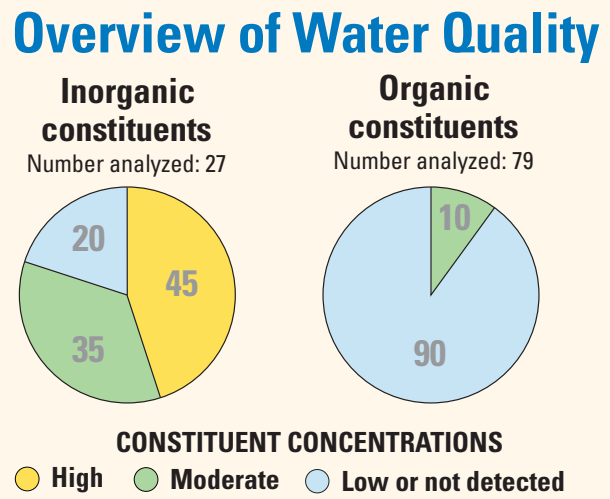

Pie charts illustrate the percentages of the primary aquifers, on an areal basis, with concentrations in the three specified categories.

GAMA’s Priority Basin Project evaluates the quality of untreated groundwater. However, for context, benchmarks established for drinkingwater quality are used for comparison. Benchmarks and definitions of high, moderate, and low concentrations are discussed in the inset box on page 3 . The USGS sampled 20 wells for this assessment; data from the California Department of Public Health database were used to supplement USGS data.

Many inorganic constituents occur naturally in groundwater. The concentrations of the inorganic constituents can be affected by natural processes as well as by human activities. In the Colorado River study area, one or more inorganic constituents were present at high concentrations in $45 \%$ of the primary aquifers and at moderate concentrations in 35\%.

Organic constituents are present in products used in the home, business, industry, and agriculture. Organic constituents can enter the groundwater system through normal usage, spills, or improper disposal. In the Colorado River study area, organic constituents were present at moderate concentrations in $10 \%$ of the primary aquifers. 


\section{RESULTS: Groundwater Quality in the Colorado River Study Area}

\section{INORGANIC CONSTITUENTS}
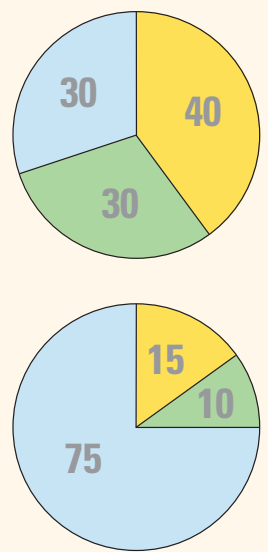

Radioactive constituents
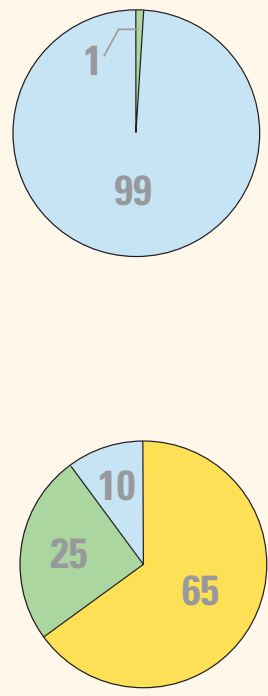

\section{Other inorganic constituents}

\section{Inorganic Constituents with Human-Health Benchmarks}

Trace elements are naturally present in the minerals in rocks and soils, and in the water that comes into contact with those materials. In the Colorado River study area, trace elements with human-health benchmarks were present at high concentrations in $40 \%$ of the primary aquifers, on an areal basis, and at moderate concentrations in $30 \%$. Of the 17 trace elements with human-health benchmarks analyzed in this study, 5 were detected at high concentrations: arsenic, boron, fluoride, molybdenum, and strontium. Chromium was detected at moderate concentrations.

Radioactivity is the release of energy or energetic particles during structural changes in the nucleus of an atom. Most of the radioactivity in groundwater comes from decay of naturally occurring isotopes of uranium and thorium that are present in minerals in the aquifer. In the Colorado River study area, radioactive constituents were detected at concentrations above benchmarks in $15 \%$ of the primary aquifers, and at moderate concentrations in $10 \%$. Six radioactive constituents were analyzed; of these, uranium and gross alpha radioactivity were detected at concentrations above benchmarks. Radon was detected at values within one-half of the proposed upper benchmark.

Nutrients, such as nitrate and nitrite, are naturally present at low concentrations in groundwater. High and moderate concentrations generally occur as a result of human activities, such as fertilizer application, livestock waste, or septic-system seepage. Of the three nutrients with health-based benchmarks analyzed, one, nitrate, was detected at moderate concentrations.

\section{Inorganic Constituents with Non-Health Benchmarks}

(Not included in water-quality overview charts shown on the front page)

Other inorganic constituents, such as total dissolved solids and manganese, affect the aesthetic properties of water, such as taste, color, or odor. In the Colorado River study area, these constituents were present at high concentrations in $65 \%$ of the primary aquifers, and at moderate concentrations in $25 \%$. Of the seven constituents with nonhealth-based benchmarks that were analyzed, five were detected at concentrations above benchmarks: chloride, iron, manganese, sulfate, and total dissolved solids.

\section{Special Interest: Perchlorate}

\section{Perchlorate}

Perchlorate is an inorganic constituent that has been regulated in California drinking water since 2007. It is an ingredient in rocket fuel, fireworks, safety flares, may be present in some fertilizers, and also occurs naturally at low concentrations in groundwater. In the Colorado River study area, perchlorate was found at moderate concentrations in $35 \%$ of the primary aquifers. 


\section{RESULTS: Groundwater Quality in the Colorado River Study Area}

\section{ORGANIC CONSTITUENTS}

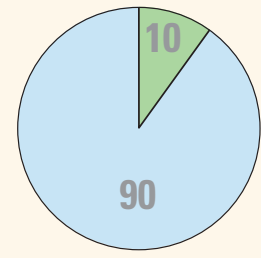

\section{Volatile organic compounds}

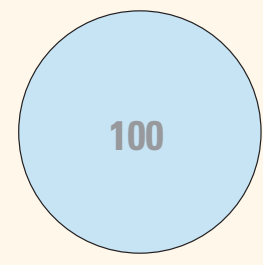

\section{Organic Constituents with Human-Health Benchmarks}

The Priority Basin Project uses laboratory methods that can detect the presence of volatile organic compounds (VOCs) and pesticides at low concentrations, far below human-health benchmarks. VOCs and pesticides detected at these low concentrations can be used to help trace water from the land surface into the aquifer system.

\section{Volatile Organic Compounds}

VOCs are present in many household, commercial, industrial, and agricultural products and are characterized by their tendency to volatilize into the air. Of 56 VOCs with health-based benchmarks analyzed in the Colorado River study area, the VOC 1,2-dichloropropane, a fumigant, was detected at moderate concentrations in $10 \%$ of the primary aquifers. All other VOCs were detected at low concentrations, or were not detected.

\section{Pesticides}

Pesticides are used on lawns, in gardens, around buildings, along roads, and in agriculture to help control unwanted vegetation (weeds), insects, fungi, and other pests. In the Colorado River study area, pesticides were not detected or were only detected at low concentrations. Of the 20 pesticides with health-based benchmarks that were analyzed, none were detected at high or moderate concentrations in the Colorado River primary aquifers.

\section{BENCHMARKS FOR EVALUATING GROUNDWATER QUALITY}

GAMA’s Priority Basin Project uses benchmarks established for drinking water to provide context for evaluating the quality of untreated groundwater. After withdrawal, groundwater may be disinfected, filtered, mixed, or exposed to the atmosphere before being delivered to consumers. Federal and California regulatory benchmarks for protecting human health (Maximum Contaminant Level, MCL) are used when available. Otherwise, nonregulatory benchmarks for protecting human health (Notification Level, NL, and Lifetime Health Advisory, HAL) and nonregulatory benchmarks for protecting aesthetic properties such as taste and odor (Secondary Maximum Contaminant Level, SMCL) are used.

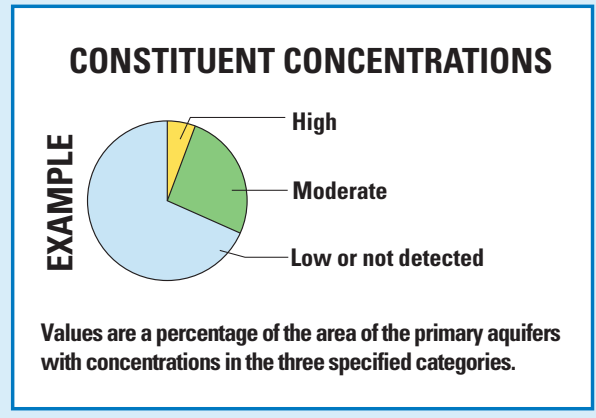

\section{High, moderate, and low concentrations are defined relative to benchmarks}

Concentrations are considered high if they are greater than a benchmark. For inorganic constituents, concentrations are moderate if they are greater than one-half of a benchmark. For organic and special-interest constituents, concentrations are considered moderate if they are greater than one-tenth of a benchmark; this lower threshold was used because organic constituents are generally less prevalent and have smaller concentrations relative to benchmarks than inorganic constituents. L ow concentrations include nondetections and values less than moderate concentrations. Methods for evaluating water quality are discussed by Milby Dawson and Belitz (2012). 


\section{Trace Element Concentrations Throughout the California Desert Region}

Trace elements were present at high concentrations in all of the Desert Region primary aquifers. In the Colorado River basins, they were high in $40 \%$ of the primary aquifers, on an areal basis; the percentage of area with high trace elements in all of the Desert Region primary aquifers ranged from 15 to 54\% (Milby Dawson and Belitz, 2012). The trace elements with the highest percentages in the Colorado River basins were fluoride (high concentrations in 20\%), strontium (10\%), and boron (10\%). Fluoride and strontium were detected at high concentrations in most of the primary aquifers in the Desert Region (five of six and four of six, respectively). Boron was detected at high concentrations in all of the primary aquifers in the Desert Region.

\section{Desert Region Study Areas}
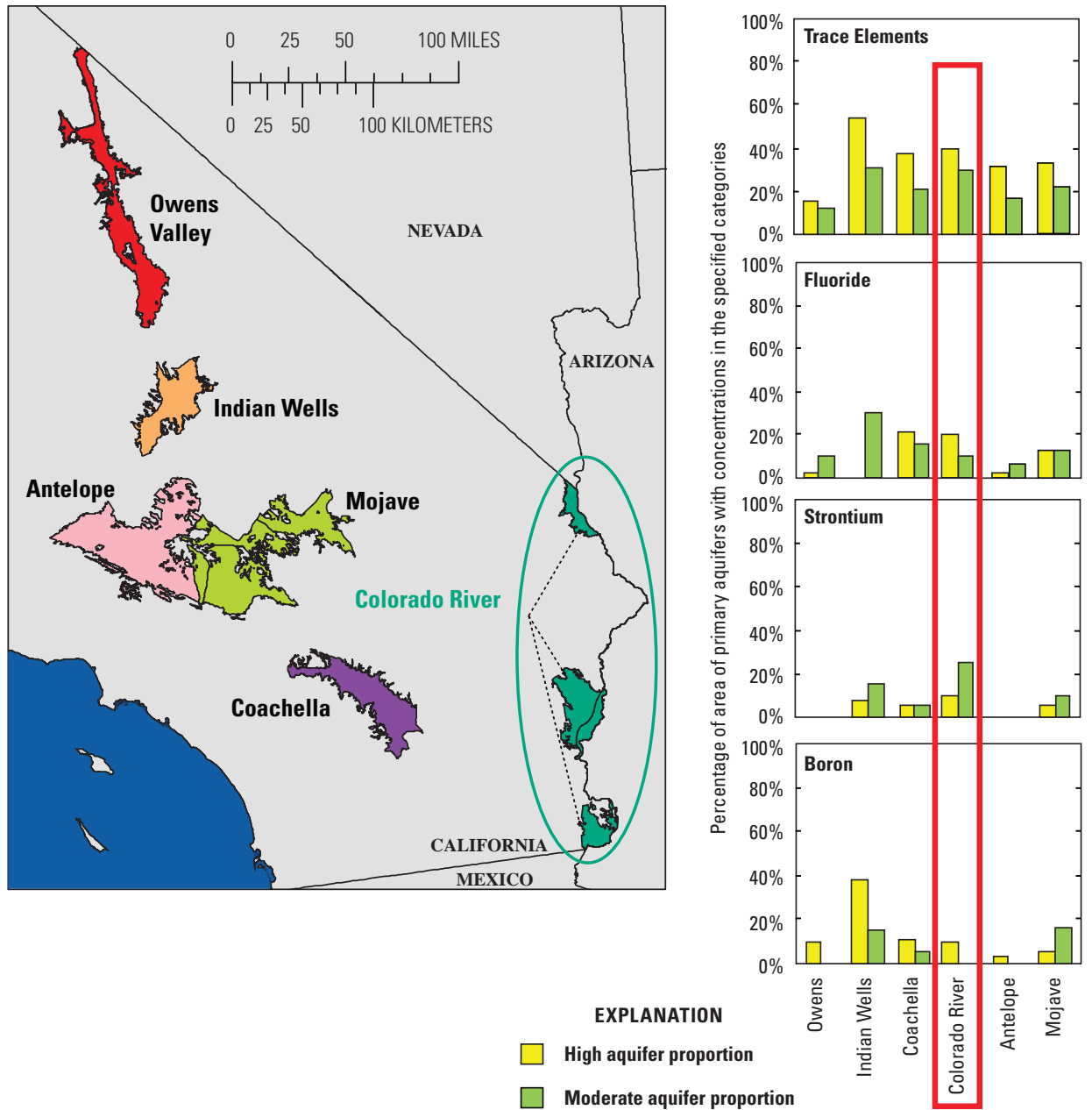

By Barbara J. Milby Dawson and Kenneth Belitz

\section{SELECTED REFERENCES}

California Department of Water Resources, 2003, California’s groundwater: California Department of Water Resources Bulletin 118, 246 p., available at http://www.water.ca.gov/groundwater/bulletin118/update2003.cfm/

Goldrath, D.A., Wright, M.T., and Belitz, K., 2010, Groundwater-quality data in the Colorado River study unit, 2007-Results from the California GAMA program: U.S. Geological Survey Data Series 474, 66 p., available at http://pubs.usgs.gov/ds/474/

Milby Dawson, B.J., and Belitz, K., 2010, Status of groundwater quality in the California Desert Region, 2006-2008-California GAMA Program Priority Basin Project: U.S. Geological Survey Scientific Investigations Report 2012-5040, 100 p.

\section{Priority Basin Assessments}

GAMA's Priority Basin Project (PBP) assesses water quality in that part of the aquifer system used for drinking water, primarily public supply. Water quality in shallower and deeper parts may differ from water quality in the primary aquifers. GAMA's Domestic Well Project assesses water quality in the shallower parts of the aquifer system. Ongoing assessments are being conducted in more than 120 basins throughout California.

The PBP assessments are based on a comparison of constituent concentrations in untreated groundwater with benchmarks established for the protection of human health and for aesthetic concerns. The PBP does not evaluate the quality of drinking water delivered to consumers.

The PBP uses two approaches for assessing groundwater quality. The first approach uses a network of wells to provide a statistically based assessment of the status of groundwater quality. The second approach uses additional wells to help assess the factors that affect water quality. Both approaches use data routinely collected for regulatory compliance, as well as data collected by the PBP. The PBP includes chemical analyses not generally available as part of regulatory compliance monitoring, including measurements at concentrations much lower than humanhealth benchmarks, and measurement of constituents that can be used to trace the sources and movement of groundwater.

\section{For more information}

Technical reports and hydrologic data collected for the GAMA Program may be obtained from:

GAMA Program Unit

U.S. Geological Survey California Water Science Center 4165 Spruance Road, Suite 200

San Diego, CA 92101

Telephone number: (619) 225-6100

WEB: http://ca.water.usgs.gov/gama

GAMA Program Unit

State Water Resources Control Board Division of Water Quality

PO Box 2231, Sacramento, CA 95812

Telephone number: (916) 341-5779

WEB: http://www.waterboards.ca.gov/gama/ 